\title{
A Complete Occlusion of Common Carotid Artery- A Case Report
}

\author{
Altina Xhaferi ${ }^{1}$, Medien Xhaferi ${ }^{2}$, Astrit Hoxhaj ${ }^{3}$ \\ ${ }^{1}$ Medical University, Faculty of Medical and Technical Sciences \\ ${ }^{2}$ University Hospital of Trauma \\ ${ }^{3}$ Hygeia Hospital, Tirana, Albania
}

\begin{abstract}
This case report describes imaging in a patient with a complete occlusion of left common carotid artery after automobile accident. There were associated findings of collaterals that supply the pattern distal ipsilateral arteries. There were found no sign of stroke. The girl was suffering problems of loose of hearing from right ear and partial facial nerve paralyzes. No specific treatment was applied to this patient except the continuing follow -up.
\end{abstract}

Keywords: common carotid artery, occlusion, collateral supply, AngioCT, Color Doppler

\section{Introduction}

Our case describes a patient with a complete occlusion of left CCA with pattern ICA and ECA and with no sign of stroke. There were associated collateral vessel that secure the blood flow in ICA and ECA

\section{Case Report}

A 24 year-old female presented with a history of two previous right ear surgeries and right facial nerve palsy. The patient was presented at sonography cabinet for her routine pre -op examinations before her third surgery in the right ear because of several episodes of ear infections. The girl has had a car accident three years ago in which she was beaten by the car in her left side and she collided the left side of her head on the pavement. From that moment she was suffering two previous ear surgeries. From that moment she was suffering even from the right facial partial paralyze.

The neck ultrasound revealed normal findings at the right side structures. On the left side was indentified total obliteration of common carotid artery. No flow was identified in Doppler exam at the obliterated area. There was notice a very thick intimae media. There was not noticed any atherosclerotic plaques. The occlusion ended just before the bifurcation.

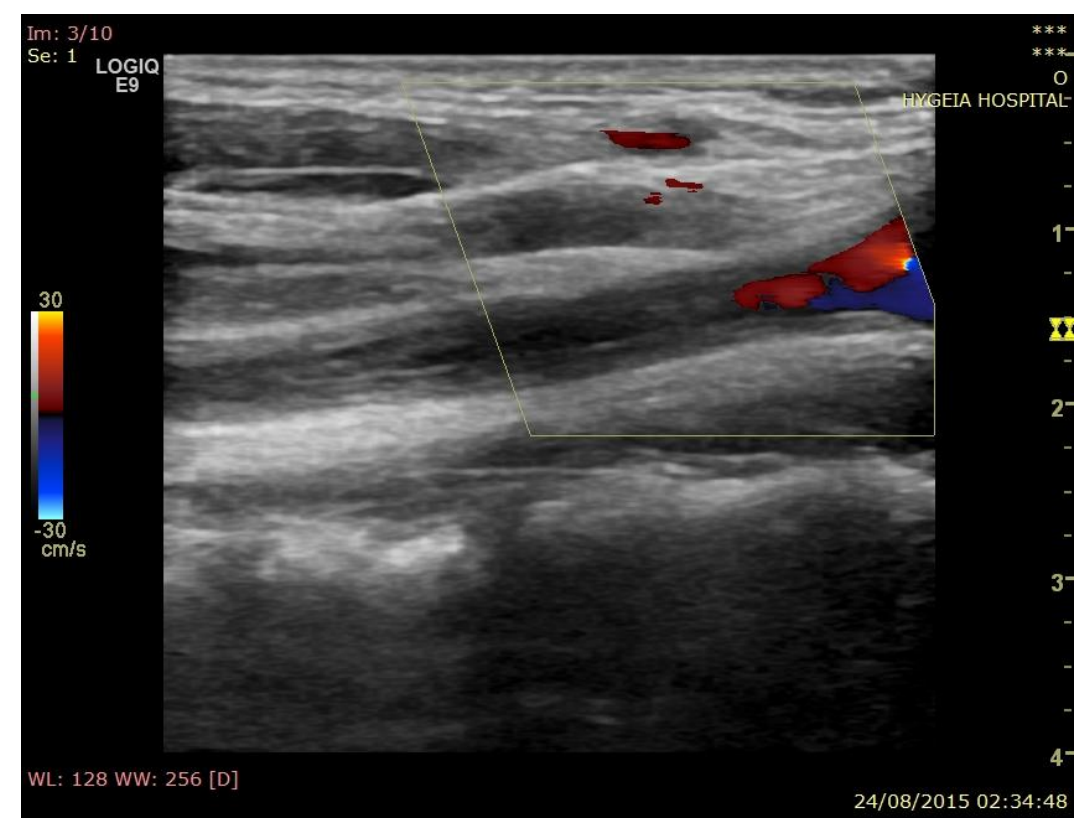

Figure 1: Ultrasound examination showing left CCA occlusion with patent distal vessels. Color mode examination: no flow in the left common carotid artery and the vessel lumen is filled with thrombotic material. 


\section{International Journal of Science and Research (IJSR) \\ ISSN (Online): 2319-7064}

Index Copernicus Value (2013): 6.14 | Impact Factor (2014): 5.611

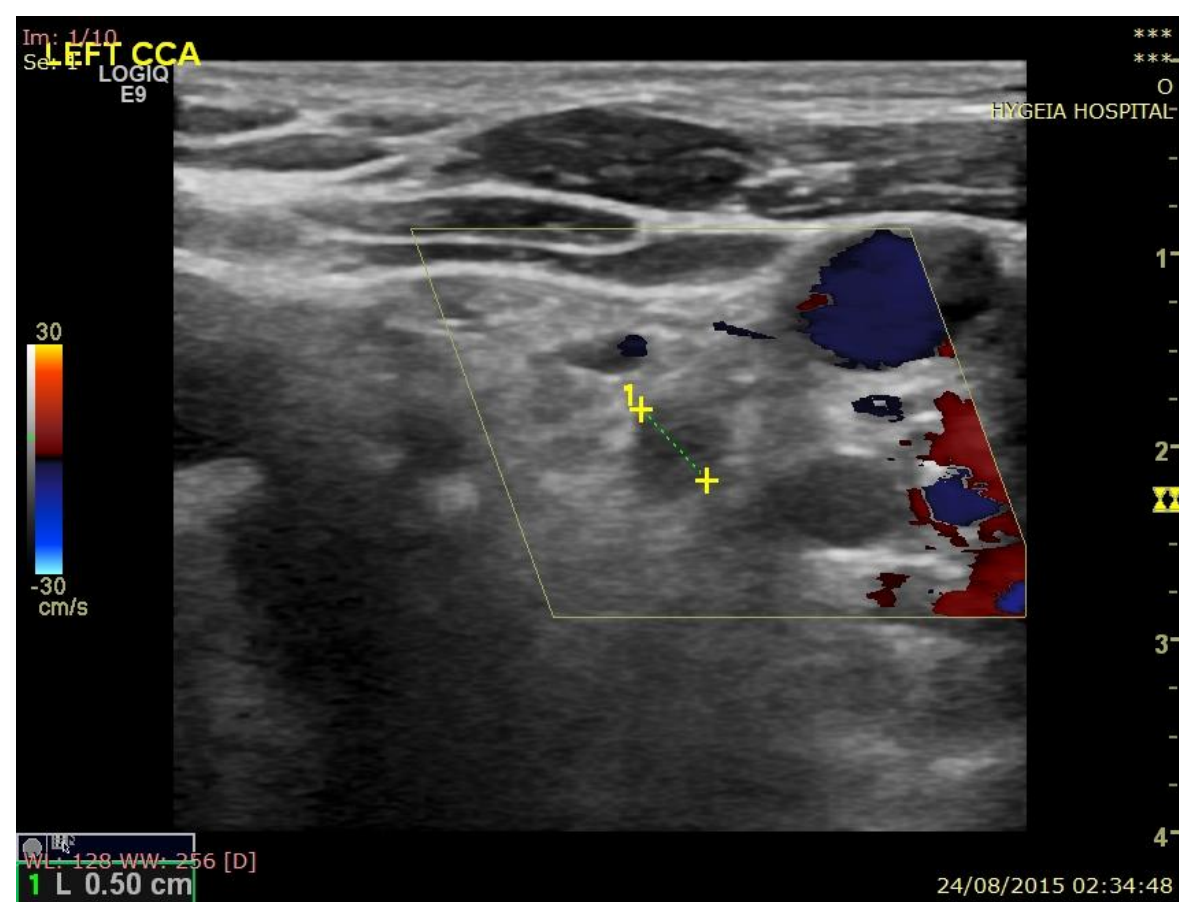

Figure 2: Ultrasound examination showing occluded left CCA. Color mode examination: LCCA occlusion, no flow in the right common carotid artery, the vessel lumen is filled with thrombotic material, and the vessel diameter is $5 \mathrm{~mm}$

Computed tomography (CT) demonstrated a total obstruction of left CCA from the bulb to the level of the bifurcation. After that pattern distal artery are noted. Although was noticed a slightly reduction of left ICA compare to right one. Normal flow and no evidence of atherosclerotic plaques were noted. Normal lumen and flow even at the bilateral vertebral arteries. Normal flow at the brain artery was revealed

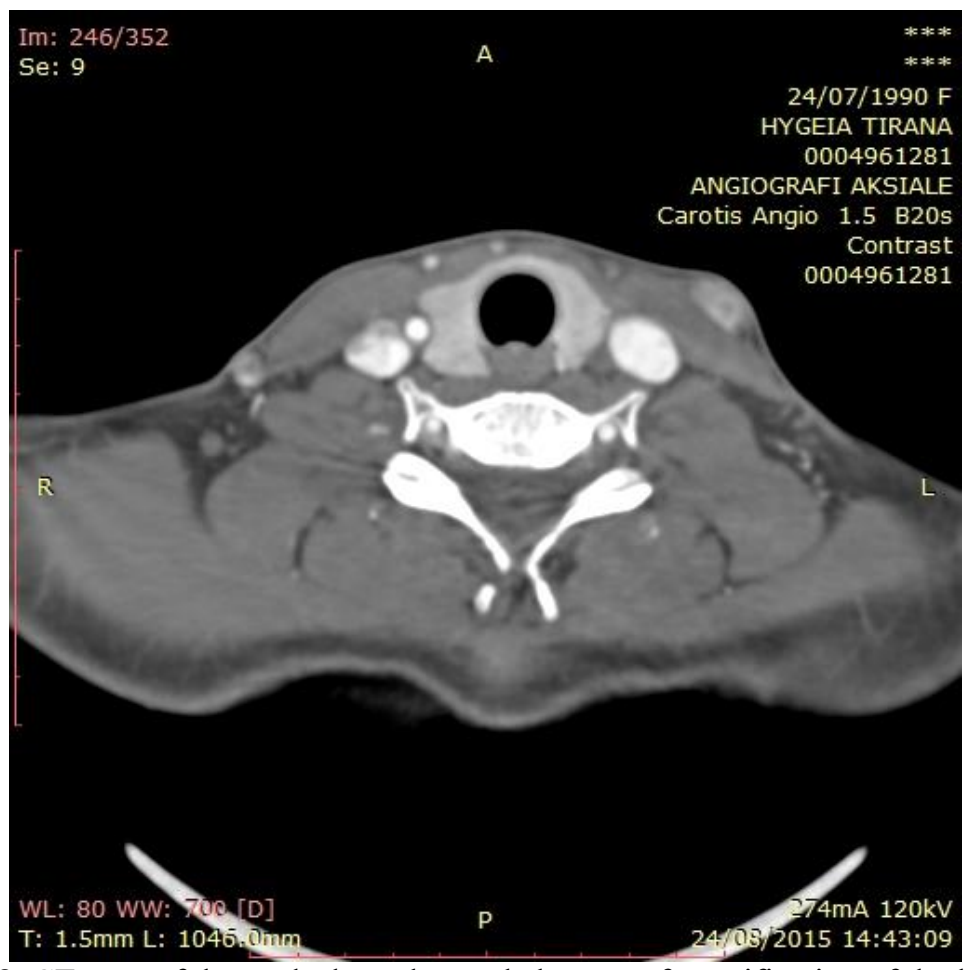

Figure 3: CT scan of the neck show the total absence of opacification of the left CCA 


\section{International Journal of Science and Research (IJSR) \\ ISSN (Online): 2319-7064}

Index Copernicus Value (2013): 6.14 | Impact Factor (2014): 5.611

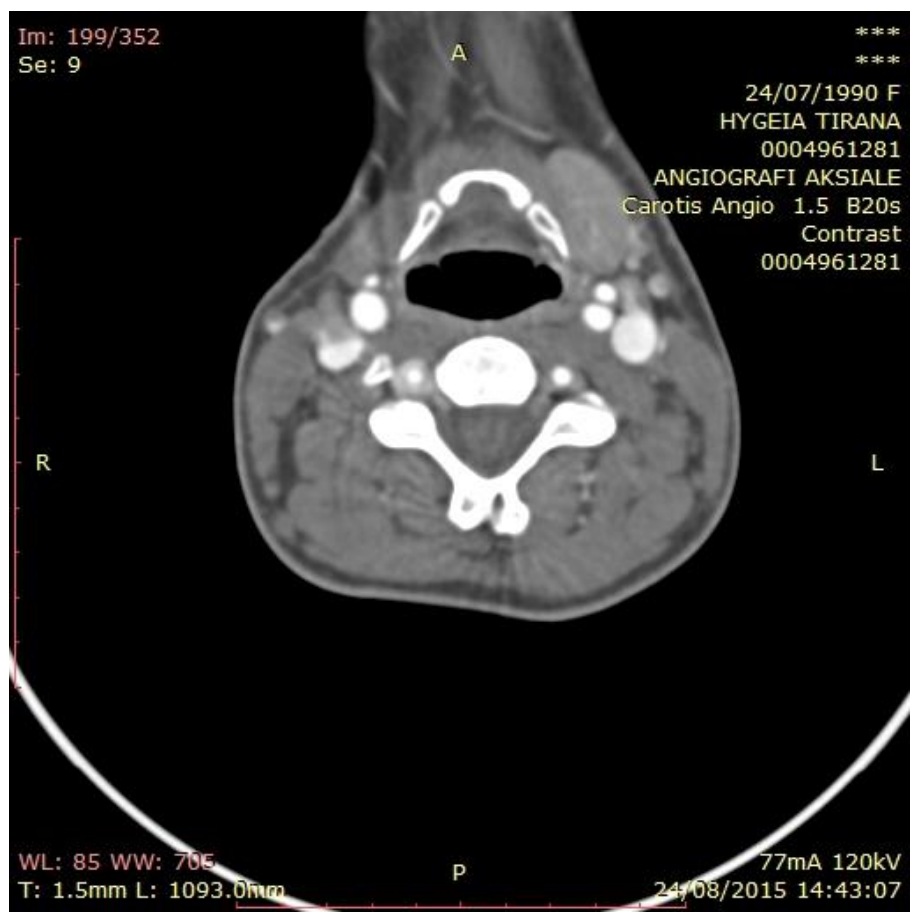

Figure 4: CT scan of the neck shows the normal flow at left ICA and ECA after the bifurcation

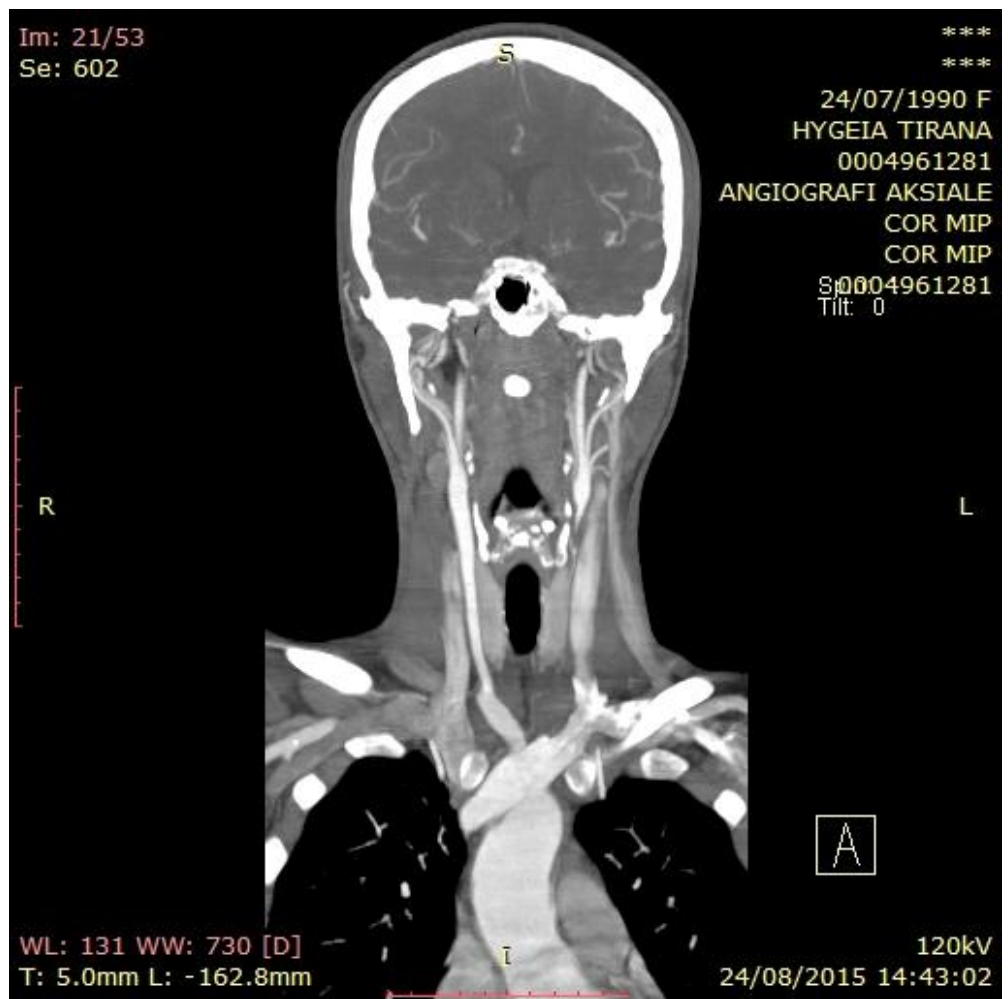

Figure 5: Volume rendering imaging of the neck shows the total obstruction of the left CCA. There were noticed collateral arteries especially from Left Subclavian Artery and left vertebral arteries that supplies the left ECA.

\section{Discussion and Review}

The clinical presentation of CCA occlusion ranges from asymptomatic to severe cerebrovascular events. The actual incidence of CCA occlusion is not known. Most of the asymptomatic cases are diagnosed accidentally,

CCA occlusion can be classified based on the patency of the distal vessels.
In Type I occlusion, there is a complete occlusion of both the CCA and the ICA. In Type II occlusion, the distal vessels are patent [1]. In Type I occlusion, ischemic events occur more frequently, suggesting a hemodynamic etiology. In Type II occlusion, the ICA is supplied by collateral blood flow via extra cranial branches through the retrograde external carotid artery. $[2,3,4]$.

Parthenis at al. [3] proposed the following detailed classifications: Type I: isolated CCA obstruction with patent distal vessels; Type Ia: flow direction from the ECA to ICA;

Volume 5 Issue 1, January 2016 


\section{International Journal of Science and Research (IJSR) \\ ISSN (Online): 2319-7064 \\ Index Copernicus Value (2013): 6.14 | Impact Factor (2014): 5.611}

Type Ib: flow direction from the ICA to ECA; Types II and III: isolated patency of the ECA and ICA; and Type IV: concomitant occlusion of both distal vessels. We did determine this case with patent distal vessels presenting with a flow direction from collaterals to ECA.

There is no data in the literature related to CCA hypoplasia as a predisposing factor for occlusion

In cases of CCA obstruction, perfusion of the ipsilateral cerebral hemisphere is provided through collateral circulation. The extra cranial collateral vessels fill the ECA in a retrograde manner and maintain the anterograde flow in the ICA. The extra cranial collateral flow originates from the ipsilateral subclavian artery via the costocervical or thyrocervical trunks and the vertebral artery and, to a lesser degree, from the contralateral ECA through the superior thyroid and lingual, facial, and occipital branches $[4,5,6]$. The flow is maintained intracranially through the circle of Willis via the anterior and posterior communicating arteries.

Arteriography remains the gold standard for accurately diagnosing carotid artery stenoocclusive disease. However, noninvasive duplex sonography, CT angiography, and MR angiography have partially replaced arteriography in daily diagnostication practice. The accuracy of duplex sonography should be much higher in the diagnosis of CCA obstruction compared to ICA occlusion due to accessibility of the CCA $[3,8,9,10]$. Arteriography has several limitations in cases of completely occluded CCA because of inadequate concentrations of contrast medium, variable collateral circulation, minimal flow in the distal branches, and poor delayed images $[11,12$,$] .$

There are little data in the literature regarding the various treatment strategies for CCA obstruction. Successful revascularization is dependent on the state of the distal branches. [8]. As a result, establishing patency of the ICA and ECA is essential prior to an intervention. [13,14,15]. Several small series reported in the literature have shown excellent revascularization results in relieving the symptoms of cerebral ischemia.

At literature review was not notice any case of trauma with artery occlusion and no sign of stroke at least till the moment of examination. In this case the collateral system was developed in order to compensate the brain blood supply

Asymptomatic carotid occlusion has a benign prognosis and most of the times require no specific treatment other than lifestyle modification and risk factor intervention [11].

\section{Conclusion}

The most frequent cause of CCA occlusion is atherosclerosis. Duplex sonography is an important noninvasive, reliable method for diagnosing CCA occlusion and establishing the patency of distal vessels. The outcome is improved in cases with patent distal vessels. In rare cases, spontaneous recanalisation is possible. Due to the low incidence of CCAO, treatment methods have not been standardized. In cases of patent distal vessels, surgical revascularization is possible, but the indications for surgery are debatable

\section{References}

[1] N. Mónica, A. Germano, L. Biscoito, and M. Baptista, -Cmmon carotid artery occlusion: doppler ultrasound findings in two patients," Journal of Diagnostic Medical Sonography, vol. 21, no. 6, pp. 502-508, 2005.

[2] T. S. Riles, A. M. Imparato, M. P. Posner, and B. C. Eikelboom, -Cmmon carotid occlusion. Assessment of the distal vessels," Annals of Surgery, vol. 199, no. 3, pp. 363-366, 1984.

[3] D. G. Parthenis, D. G. Kardoulas, C. V. Ioannou et al., Fotal occlusion of the common carotid artery: a modified classification and its relation to clinical status," Ultrasound in Medicine and Biology, vol. 34, no. 6, pp. 867-873, 2008.

[4] S.-L. Lai, Y.-C. Chen, H.-H. Weng, S.-T. Chen, S.-P. Hsu, and T.-H. Lee, Bilateral common carotid artery occlusion - a case report and literature review," Journal of the Neurological Sciences, vol. 238, no. 1-2, pp. 101104, 2005

[5] R. Pretre, A. Kalangos, M. Bednarkiewicz, I. Bruschweiler, and B. Faidutti, - Reersed flow in the internal carotid artery after occlusion of the common carotid artery," Thoracic and Cardiovascular Surgeon, vol. 42, no. 6, pp. 358-360, 1994.

[6] M. Belkin, W. C. Mackey, M. S. Pessin, L. R. Caplan, T. F. O'Donnell, and D. B. Pilcher, Eommon carotid artery occlusion with patent internal and external carotid arteries: diagnosis and surgical management," Journal of Vascular Surgery, vol. 17, no. 6, pp. 1019-1028, 1993.

[7] C.-F. Tsai, J.-S. Jeng, C.-J. Lu, and P.-K. Yip, —Ghical and ultrasonographic manifestations in major causes of common carotid artery occlusion," Journal of Neuroimaging, vol. 15, no. 1, pp. 50-56, 2005.

[8] T. Baumann, A. J. Steck, and P. Lyrer, - Atiologies, clinical and vascular findings in symptomatic and asymptomatic carotid artery occlusion," Schweizer Archiv für Neurologie und Psychiatrie, vol. 153, no. 7, pp. 316-320, 2002.

[9] Zoltán Bajkó, Rodica Bălaşa, Anca Moţăţăianu, Smaranda Maier, Octavia Claudia Chebuţ, and Szabolcs Szatmári, Common Carotid Artery Occlusion: A Case Series": ISRN Neurology Volume 2013

[10] J. M. Valdueza, S. J. Schreiber, J. E. Roehl, and R. Klingebiel, Neurosonology and Neuroimaging of Stroke, Thieme, Stuttgart, Germany, 2008.

[11]Dimmick SJ, Faulder KC. Normal variants of the cerebral circulation at multidetector CT angiography. Radiographics. 2009;29:1027-1043.

[12] J. Li, D. Shi, Y. Wei, J. Xiao, K. Zhang, and M. Wang, Blood flow in the internal carotid artery with common carotid artery-occluding lesions in Takayasu arteritis," Journal of Ultrasound in Medicine, vol. 29, no. 11, pp. 1547-1553, 2010.

[13]Q. A. Shah, Spontaneous recanalization after complete occlusion of the common carotid artery with subsequent embolic ischemic stroke," Journal of Vascular and Interventional Neurology, vol. 2, pp. 147-151, 2009. 


\section{International Journal of Science and Research (IJSR) \\ ISSN (Online): 2319-7064}

Index Copernicus Value (2013): 6.14 | Impact Factor (2014): 5.611

[14] R. S. Martin III, W. H. Edwards, J. L. Mulherin Jr., and W. H. Edwards Jr., Surgical treatment of common carotid artery occlusion," The American Journal of Surgery, vol. 165, no. 3, pp. 302-306, 1993.

[15]W. J. Powers, Management of patients with atherosclerotic carotid occlusion," Current Treatment Options in Neurology, vol. 13, no. 6, pp. 608-615, 2011. 